\title{
PSEUDOPEROXIDASE ACTIVITY OF SILVER NANOPARTICLES (AgNPs) AND CHANGES IN PEROXIDASE ACTIVITY IN MAIZE PLANTS EXPOSED TO AgNPS
}

\author{
1'Zuzana TOTHOVA, 1,2,3Karel SEHNAL, 1,2Dagmar UHLIROVA, 1,2Martina STANKOVA, \\ 1,2 Michaela VSETICKOVA, ${ }^{2}$ Bozena HOSNEDLOVA, ${ }^{4}$ Marta KEPINSKA, ${ }^{2,3}$ Branislav RUTTKAY- \\ NEDECKY, ${ }^{1}$ Josef RUZICKA, ${ }^{1,3,5}$ Yagmur OZDOGAN, ${ }^{6}$ Carlos FERNANDEZ, \\ ${ }^{4}$ Halina MILNEROWICZ, ${ }^{2}$ Jiri SOCHOR, ${ }^{1,2,3,4}$ Rene KIZEK \\ ${ }^{1}$ Department of Research and Development, Prevention Medicals s.r.o., Studenka-Butovice, \\ Czech Republic, EU, uhlirova@preventionmedicals.cz \\ ${ }^{2}$ Department of Viticulture and Enology, Faculty of Horticulture, Mendel University in Brno, Lednice, \\ Czech Republic, EU, bozena.hosnedlova@post.cz \\ ${ }^{3}$ Department of Human Pharmacology and Toxicology, University of Veterinary and Pharmaceutical \\ Sciences Brno, Brno, Czech Republic, EU, kizek@sci.muni.cz \\ ${ }^{4}$ Department of Biomedical and Environmental Analyses, Faculty of Pharmacy with Division of Laboratory \\ Diagnostics, Wroclaw Medical University, Wroclaw, Poland, EU, zalewska.m@gmail.com \\ ${ }^{5}$ School of Pharmacy, Altinbas University, Faculty of Pharmacy, Mahmutbey Mahallesi, Bagcılar/lstanbul, \\ Turkey \\ ${ }^{6}$ School of Pharmacy and Life Sciences, Robert Gordon University, Garthdee Road, Aberdeen, Scotland, \\ United Kingdom, EU, c.fernandez@rgu.ac.uk
}

https://doi.org/10.37904/nanocon.2019.8511

\begin{abstract}
Some types of nanoparticles such as gold and silver show interesting chemical properties. Pseudoperoxidase activity has been found in iron- or gold-based materials, but some silver nanoparticles (AgNPs) also exhibit such properties. Pseudoperoxidase activity of AgNPs prepared by green synthesis using sage leaves was studied. The AgNPs (prepared by green synthesis using sage leaves) size ranged from 20 to $50 \mathrm{~nm}$ and zeta potential was found to vary from -10 to $20 \mathrm{mV}$, with absorption maximum being $430 \mathrm{~nm}$. The peroxidase-like

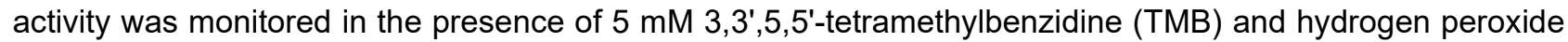
(30\%). The nanoparticles showed about $80 \%$ activity of $1 \mathrm{mU}$ horseradish peroxidase (HRP). In addition, AgNPs were applied to maize seedlings (5 days in hydroponics system) at concentrations of $1 \mathrm{mg} / \mathrm{L}, 50 \mathrm{mg} / \mathrm{L}$, and $150 \mathrm{mg} / \mathrm{L}$. Peroxidase activity in leaves after 48 hours was $59.5,67.5$, and $57.2 \mu \mathrm{g} \cdot \mathrm{mL}^{-1}$ of HRP, respectively. Peroxidase activity of untreated plant leaves was $58.8 \mu \mathrm{g} \cdot \mathrm{mL}^{-1}$ of HRP. Peroxidase activity in roots after 48 hours was $101.6,109.0$, and $156.7 \mu \mathrm{g} \cdot \mathrm{mL}^{-1}$ of HRP, respectively. The peroxidase activity level of the control variant in root of treatment was $98.7 \mu \mathrm{g} \cdot \mathrm{mL}^{-1}$ of HRP. The results indicate that the determination of peroxidase activity could be used to assess the phytotoxicity of nanoparticles in plants.
\end{abstract}

Keywords: Green synthesis, toxicity of nanoparticles, enzymatic activity, maize, nanotoxicity

\section{INTRODUCTION}

With the development of nanotechnologies and their subsequent applications in biology, there is considerable interest in their use in nanomedicine, in particular in the field of drug delivery, imaging or biological separation techniques. Despite the fact that nanoparticles have shown adverse effects, they are almost biologically and chemically stable [1]. Silver nanoparticles (AgNPs) are one of the most commonly used nanomaterials in various fields. Silver nanoparticles exhibit significant antibacterial effects thereby providing excellent potential for industrial applications [2]. In addition, ongoing climate change will lead to dramatic changes in ecosystems, 
including bacteria [3]. Thus, the need to create new ways of protecting human and animal health from dangerous infections can be expected. As a result of their increased use, nanoparticles will increasingly be released into the environment and therefore knowledge of their effects on other living organisms is important. In addition, biological interactions and relationships that have not yet been described may be revealed [4]. More detailed information on the effect of nanoparticles on plants, including translocation and role in plant metabolism has been summarized by Faraz et al. [5]. In several works, AgNPs were prepared with the use of maize extracts [6,7]. After the administration of AgNPs, anatomical changes in maize plants and accumulations of the nanoparticles in their roots were observed [8]. Thus, finding suitable biochemical markers to assess the plant's stress response is a challenge [9]. In plants, phenolic compounds, flavonoids, antioxidant enzymes and others are commonly analysed. In addition, plants respond to the presence of heavy metal ions by the synthesis of thiol compounds (glutathione, phytochelatins) $[10,11]$. Horseradish peroxidase (HRP) is known to be an oxidoreductase that uses peroxide to oxidize many organic and inorganic substrates. HRP is also the most widely used enzyme in biotechnological applications where it provides a color reaction in the presence of hydrogen peroxide and a suitable chromogen 3,3',5,5'-tetramethylbenzidine (TMB) [12]. However, a significant disadvantage is its biological instability. The peroxidase-like activity has been reported in some types of nanoparticles, such as iron or gold $[13,14]$. The advantage of such particles is their excellent stability at normal and extreme temperatures, $\mathrm{pH}$, etc. The aim of this work was to study the effect of different concentrations of $\mathrm{AgNPs}$ and silver nitrate $\left(\mathrm{AgNO}_{3}\right)$ on maize seedlings (Zea mays) and the assessment of their peroxidase activity.

\section{MATERIAL AND METHODS}

Chemicals. All chemicals used in this study such silver nitrate, methanol, $\mathrm{NaCl}, 3,3^{\prime}, 5,5^{\prime}$-tetramethylbenzidine (TMB), $\mathrm{H}_{2} \mathrm{O}_{2}\left(30 \%\right.$ ), mercaptosuccinic acid (MSA), $\mathrm{Na}_{2} \mathrm{HPO}_{4}, \mathrm{NaH}_{2} \mathrm{PO}_{4}, \mathrm{HNO}_{3}$, Trizma base and $\mathrm{HCl}$ were purchased from Merck (USA), in ACS purity. Propanol and $\mathrm{NaBH}_{4}$ were purchased from Merck (USA), and $25 \%$ aqueous $\mathrm{NH}_{4} \mathrm{OH}$ was purchased from Lach-Ner, s.r.o. (Neratovice, Czech Republic). All chemicals that we used for gel electrophoresis were purchased from VWR (Germany). All plastic materials used (tubes, tips) in this study were purchased from Eppendorf (Hamburg, Germany). Deionised water was prepared by using the reverse osmosis equipment Aqual 25 (Brno, Czech Republic), and was further purified by using an ELGA apparatus equipped with a UV lamp (Lane End, United Kingdom). Instruments. The absorbance spectra of nanoparticles were recorded using a UV-3100PC UV-VIS spectrophotometer (VWR, USA). Plant cultivation. Maize seeds (Zea mays) of Silen variety were sprouted on cellulose wadding in cultivation boxes (BATIST Medical a.s., Czech Republic) in an amount of $3 \times 5$ seeds and were watered by tap water $(250 \mathrm{~mL}$, conductivity of $480 \mu \mathrm{S} / \mathrm{cm}, \mathrm{pH}$ 6.5). The boxes were left for one week at $25{ }^{\circ} \mathrm{C}$. For our experiment, 5-day-old maize seedlings were selected. The plants were chosen to be uniform in size. After this time the seedlings were placed into a hydroponic system with $3 \mathrm{~L}$ of cultivation solution and with a light of $36 \mathrm{~W} / 865$, FAR of 100 $\mu \mathrm{mol} / \mathrm{m}^{2} / \mathrm{s}$ with light/dark intervals of $12 \mathrm{~h} / 12 \mathrm{~h} . \mathrm{AgNO}_{3}$ and AgNPs were applied at 1, 50, $150 \mathrm{mg} / \mathrm{L}$. Distilled water was used as a negative control. Plant sample preparation. Physiological and morphological evaluation of plants: Stem (weight, length, number of leaves, shortest leaf, longest leaf) and root (weight, length of longest and shortest root, number of roots) morphology in the plants was observed. Other experimental details are given in Sehnal [15]). Peroxidase assay. A substrate was prepared to contain acetate buffer $\mathrm{pH} 4(0.5 \mathrm{M})$, TMB $(5 \mathrm{mM})$ and $\mathrm{H}_{2} \mathrm{O}_{2}(30 \%)$. The substrate $(200 \mu \mathrm{L})$ was pipetted into a pre-washed plate and $10 \mu \mathrm{L}$ of the sample was added. Measurement was done at room temperature for $30 \mathrm{~min}$ at $620 \mathrm{~nm}$ (Infinite F50, TECAN, Switzerland). The obtained kinetic curves were mathematically analyzed. Statistical analysis of data. Experimental work was performed in at least three independent experiments. Each sample in the experiments was analysed at least five times. The obtained data presented in this paper are the average values. No experimental points were excluded from the proposed experimental study. All the obtained data were stored in the Qinslab database (Prevention Medicals, CR). If possible, data were processed and evaluated 
mathematically and statistically in the Qinslab database. The results were expressed as mean \pm standard deviation (SD). Photos were processed by the ColorTest program (Prevention Medical), which assigns an intensity to the individual pixels of the studied image in a given color area. For preparing the publication, the data were processed using MICROSOFT software (USA).

\section{RESULTS AND DISCUSSION}

Peroxidase reaction participates in many biochemical pathways and biotechnological applications [16] due to the fact that some groups of compounds or nanomaterials may possess enzyme (also peroxidase) activity [16-18]. As shown in Figure 1, since 2015, the number of outputs regarding this research has dramatically increased.

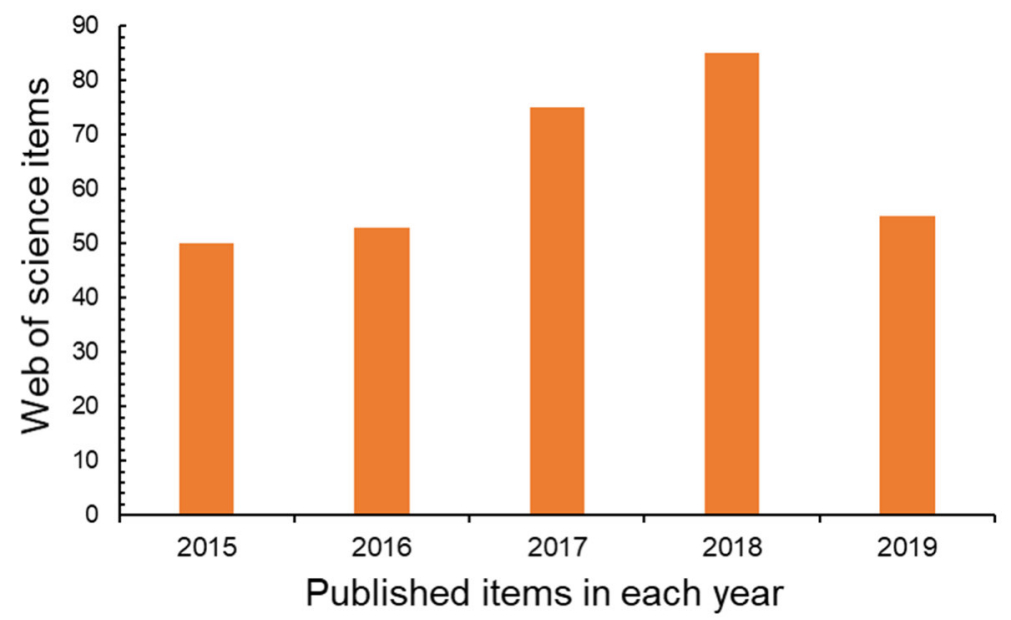

Figure 1 Number of items for the keyword "peroxidase-like activity" in Web of Science, data was evaluated for the years 2015 and 2019 (to the date of 30/7/2019).

Finding suitable markers for plant stress response caused by nanoparticles action is a challenge. Plants including agriculturally very intensively used species such as maize could be exposed to nanoparticles present in the environment. However, there is very little information about the effect of AgNPs on maize in research studies. In previous experimental work, AgNPs were prepared by green synthesis. The nanoparticles were spherical in shape with sizes of $20-50 \mathrm{~nm}$ and the absorption maximum was around $430 \mathrm{~nm}$. The prepared nanoparticles were further precipitated with methanol and dried at $60^{\circ} \mathrm{C}$. They were then re-dispersed in water and used for this experiment. We found that AgNPs showed pseudoperoxidase activity by oxidizing the TMB substrate. A typical blue TMB color reaction was generated (Figure 3). AgNPs showed significant temperature $\left(-20\right.$ to $\left.+100{ }^{\circ} \mathrm{C}\right)$ and $\mathrm{pH}(2$ to 14$)$ stability compared to HRP. In addition, long-term stability at the ambient temperature of about $25{ }^{\circ} \mathrm{C}$ was studied. No difference in peroxidase activity was observed over 30 days (95-100\% of original signals) after 6 months of AgNPs storage, pseudoperoxidase activity reached $85-$ $95 \%$ activity of freshly prepared AgNPs. AgNPs prepared in this way showed antibacterial properties (Sehnal et al. - unpublished results). AgNPs were applied to maize seedlings (5 days in hydroponics system). The maize plants were exposed to $\mathrm{AgNO}_{3}$ and AgNPs for $120 \mathrm{~h}$. Physiological growth parameters were evaluated at $24,48,96$, and $120 \mathrm{~h}$. Significant growth depression (statistically significant) was observed in plants exposed to $\mathrm{AgNPs}$ and $\mathrm{AgNO}_{3}$ (from 70 to $60 \%$ of the control). With increasing concentration and time exposure, there was an increase in total growth depression mainly in the variant with $\mathrm{AgNO}_{3}(50 \%$ of the control). In the AgNPs variant, the variability of results was observed but the average value was $102 \%$ of the control. Significant effects were observed in the variant exposed to $\mathrm{AgNO}_{3}$. The observed effects on growth were statistically insignificant to the control at the concentration of $1 \mathrm{mg} / \mathrm{L} \mathrm{AgNPs}$. 

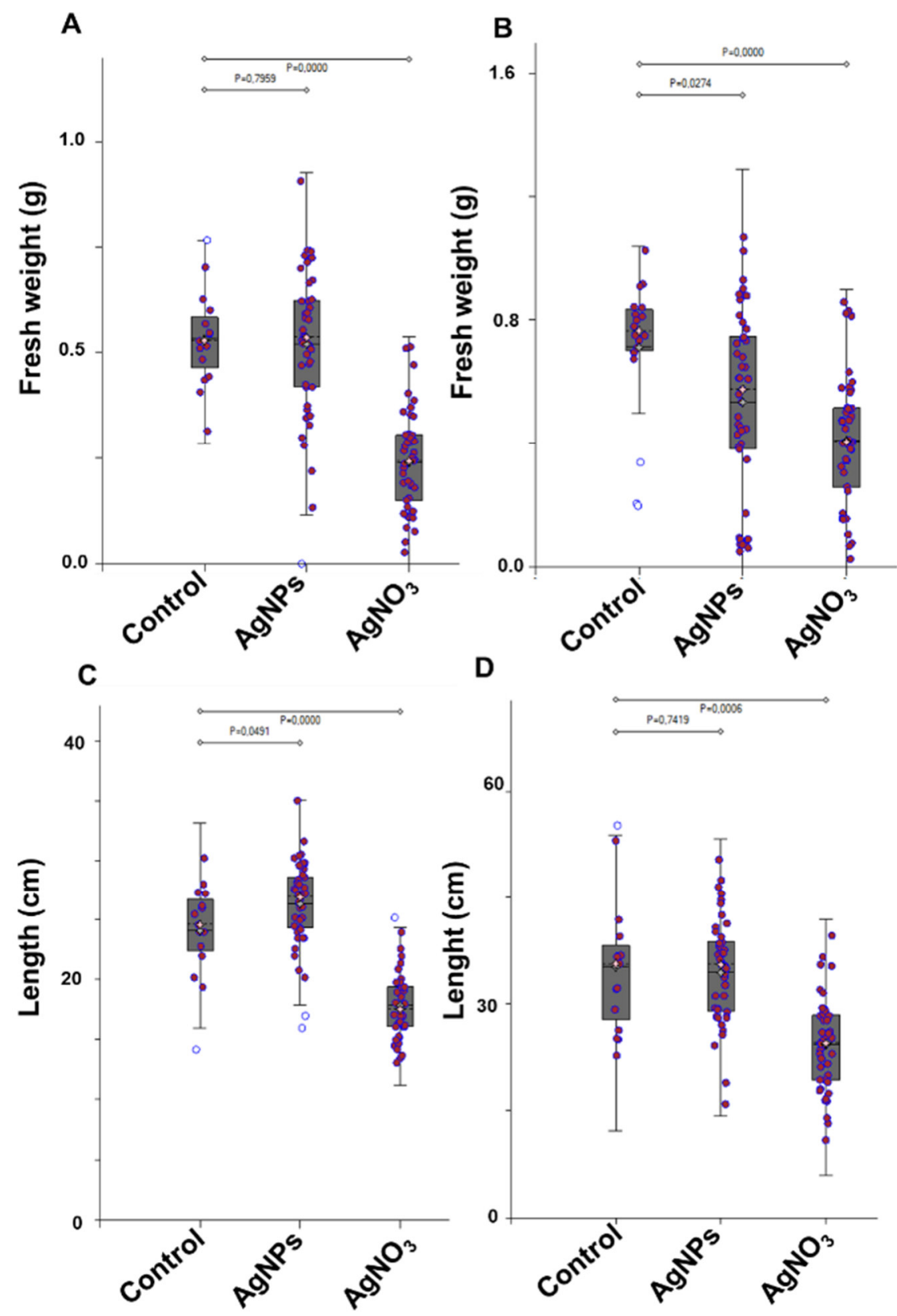

Figure 2 Cumulative effects of $\mathrm{AgNPs}$ and $\mathrm{AgNO}_{3}$ (control,1, 50, and $150 \mathrm{mg} / \mathrm{L}$ ) on maize plants:

A) leave weight, $B$ ) root weight, $C$ ) leaf length, D) root length

The maize plants treated with $\mathrm{AgNPs}$ and $\mathrm{AgNO}_{3}$ looked similar to the control variant. In the variants with $\mathrm{AgNO}_{3}$, color changes and a very intense change in leaf turgor were visible. Evidently, the variant with $\mathrm{AgNO}_{3}$ was more toxic to plants. In addition, increases in levels of thiol compounds have been observed in plants exposed to metal ions. Peroxidase activity was tested for each test variant (Figure 2). We found that plant extracts from both leaves and roots showed peroxidase activity. AgNPs were applied at concentrations of 1 $\mathrm{mg} / \mathrm{L}, 50 \mathrm{mg} / \mathrm{L}$, and $150 \mathrm{mg} / \mathrm{L}$. The peroxidase activity level of the control variant in leaf after 48 hours of treatment was $58.8 \mu \mathrm{g} \cdot \mathrm{mL}^{-1}$ of HRP. Peroxidase activity in leaves was $59.5,67.5$, and $57.2 \mu \mathrm{g} \cdot \mathrm{mL}^{-1}$ of HRP, respectively. The peroxidase activity level of the control variant in root after 48 hours of treatment was 98.7 $\mu \mathrm{g} \cdot \mathrm{mL}^{-1}$ of HRP. Peroxidase activity in roots was $101.6,109.0$, and $156.7 \mu \mathrm{g} \cdot \mathrm{mL}^{-1}$ of HRP, respectively. Typical images of samples in the visual test for peroxidase activity are shown in Figure 3. 


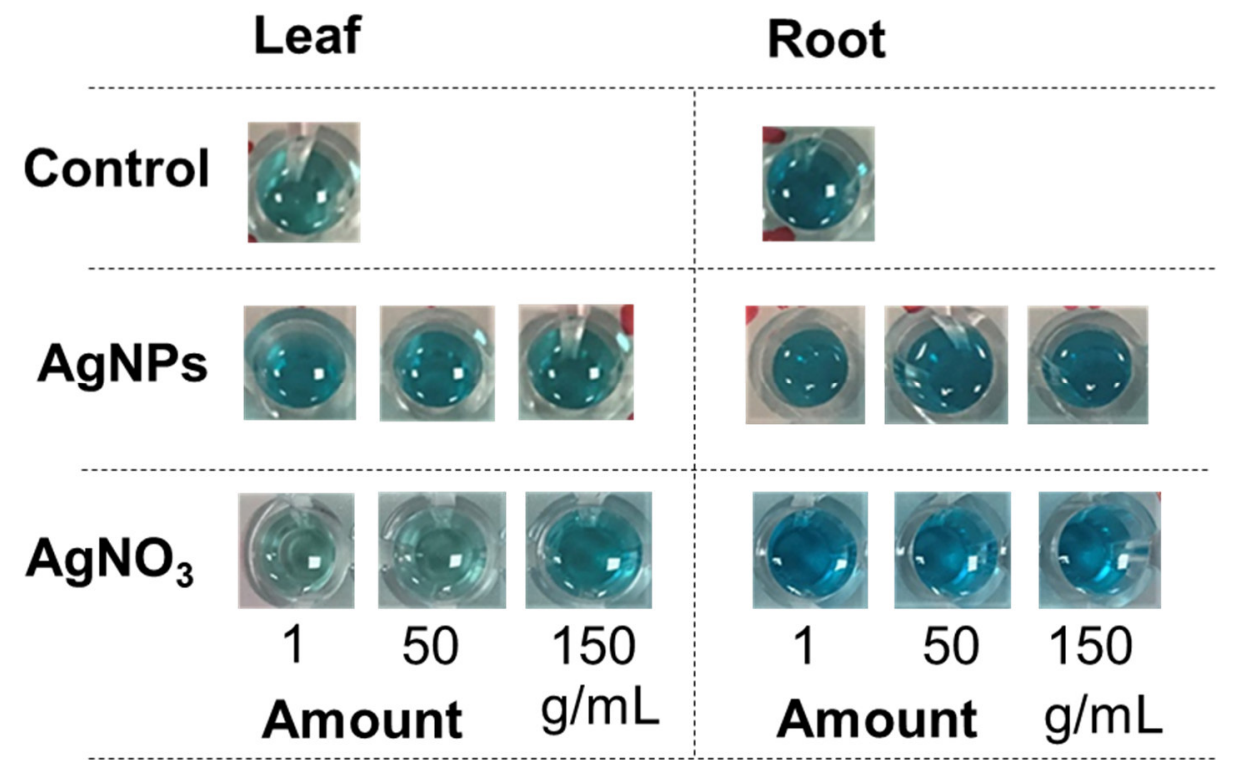

Figure 3 Typical images of samples in the visual test for peroxidase activity after 30 minutes. $200 \mu \mathrm{L}$ of solution ( $\mathrm{TMB}, \mathrm{H}_{2} \mathrm{O}_{2}$, and acetate buffer $\mathrm{pH} 4$ ) and $10 \mu \mathrm{L}$ of the sample was pipetted into microtitration plate well.

\section{CONCLUSION}

It was found that AgNPs prepared by green synthesis showed pseudoperoxidase activity and are thus able to decompose hydrogen peroxide to water. $\mathrm{AgNPs}$ and $\mathrm{AgNO}_{3}$ were applied to maize plants in a hydroponic experiment (for 5 days). We found biological effects concerning both nanoparticles and silver ions. Statistical analysis showed that plants treated with silver nanoparticles exhibited a much higher weight and a much greater length than those treated with silver nitrate. Size of nanoparticles and their easy transport from root to leaves through xylem can be the reason of this result. We found that plants treated with nanoparticles had less peroxidase activity compared to plants treated with silver ions. It has been shown that nanoparticles are less phytotoxic for plants according to metal ions. Silver ions have been shown evident phytotoxicity on maize plants. Thus, peroxidase activity can be used as detector of phytotoxicity. In addition, peroxidase activity from the above-ground plant parts and root extracts of the maize was studied. Peroxidase activity was found to increase in the variants tested.

\section{ACKNOWLEDGEMENTS}

The work was carried out with the support of the H2020 CA COST Action CA15114, INTER-COST LTC18002.

\section{REFERENCES}

[1] SHARIFI, S., BEHZADI, S., LAURENT, S., FORREST, M. L., STROEVE, P., MAHMOUDI, M. Toxicity of nanomaterials. Chemical Society Reviews, 2012, vol. 41, no. 6, pp. 2323-2343.

[2] PENG, B., ZHANG, X. L., AARTS, D., DULLENS, R. P. A. Superparamagnetic nickel colloidal nanocrystal clusters with antibacterial activity and bacteria binding ability. Nature Nanotechnology, 2018, vol. 13, no. 6, pp. 478-486.

[3] MAUTER, M. S., ZUCKER, I., PERREAULT, F., WERBER, J. R., KIM, J. H., ELIMELECH, M. The role of nanotechnology in tackling global water challenges. Nature Sustainability, 2018, vol. 1, no. 4, pp. 166-175. 
[4] AKTER, M., SIKDER, M. T., RAHMAN, M. M., ULLAH, A., HOSSAIN, K. F. B., BANIK, S., HOSOKAWA, T., SAITO, T., KURASAKI, M. A systematic review on silver nanoparticles-induced cytotoxicity: Physicochemical properties and perspectives. Journal of Advanced Research, 2018, vol. 9, no. pp. 1-16.

[5] FARAZ, A., FAIZAN, M., SAMI, F., SIDDIQUI, H., PICHTEL, J., HAYAT, S. Nanoparticles: biosynthesis, translocation and role in plant metabolism. let Nanobiotechnology, 2019, vol. 13, no. 4, pp. 345-352.

[6] EREN, A., BARAN, M. F. Green synthesis, characterization and antimicrobial activity of silver nanoparticles (AgNPs) from maize (Zea mays L.). Applied Ecology and Environmental Research, 2019, vol. 17, no. 2, pp. 40974105.

[7] TONG, X. L., GUO, N., DANG, Z. Y., REN, Q. G., SHEN, H. In vivo biosynthesis and spatial distribution of Ag nanoparticles in maize (Zea mays L.). let Nanobiotechnology, 2018, vol. 12, no. 7, pp. 987-993.

[8] JAFARI, S., DAVOODI, D., JONOUBI, P., MAJD, A., ALIZADEH, H., SHOBBAR, Z. S. Anatomical assessment of maize (Zea mays L.) seedlings exposed to colloidal silver nanoparticles Applied Ecology and Environmental Research, 2018, vol. 16, no. 3, pp. 2391-2401.

[9] YUAN, L., RICHARDSON, C. J., HO, M., WILLIS, C. W., COLMAN, B. P., WIESNER, M. R. Stress Responses of Aquatic Plants to Silver Nanoparticles. Environmental Science \& Technology, 2018, vol. 52, no. 5, pp. 2558-2565.

[10] GAWEL, J. E., AHNER, B. A., FRIEDLAND, A. J., MOREL, F. M. M. Role for heavy metals in forest decline indicated by phytochelatin measurements. Nature, 1996, vol. 381, no. 6577, pp. 64-65.

[11] MARCHIONI, M., GALLON, T., WORMS, I., JOUNEAU, P. H., LEBRUN, C., VERONESI, G., TRUFFIERBOUTRY, D., MINTZ, E., DELANGLE, P., DENIAUD, A., MICHAUD-SORET, I. Insights into polythiol-assisted AgNP dissolution induced by bio-relevant molecules. Environmental Science-Nano, 2018, vol. 5, no. 8, pp. 19111920.

[12] VEITCH, N. C. Horseradish peroxidase: a modern view of a classic enzyme. Phytochemistry, 2004, vol. 65, no. 3, pp. 249-259.

[13] DOCEKALOVA, M., UHLIROVA, D., STANKOVA, M., KEPINSKA, M., SOCHOR, J., MILNEROWICZ, H., BABULA, P., FERNANDEZ, C., BRAZDOVA, M., ZIDKOVA, J., SUCHY, P., KIZEK, R., CZECH SOC NEW, M., TECHNOL, REGION CTR ADV, T., MAT Characterisation of peroxidase-like activity of thermally synthesized gold nanoparticles 8th International Conference on Nanomaterials - Research \& Application, 2017, vol., no. pp. 429434.

[14] DENG, H. H., HONG, G. L., LIN, F. L., LIU, A. L., XIA, X. H., CHEN, W. Colorimetric detection of urea, urease, and urease inhibitor based on the peroxidase-like activity of gold nanoparticles. Analytica Chimica Acta, 2016, vol. 915, no. pp. 74-80.

[15] SEHNAL, K. An assessment of the effect of green synthesized silver nanoparticles using sage leaves (Salvia officinalis L.) on germinated plants of maize (Zea mays L.). in preparation, 2019, vol., no. pp.

[16] GAO, L., ZHUANG, J., NIE, L., ZHANG, J., ZHANG, Y., GU, N., WANG, T., FENG, J., YANG, D., PERRETT, S., YAN, X. Intrinsic peroxidase-like activity of ferromagnetic nanoparticles. Nature Nanotechnology, 2007, vol. 2, no. 9, pp. 577-583.

[17] JV, Y., LI, B., CAO, R. Positively-charged gold nanoparticles as peroxidiase mimic and their application in hydrogen peroxide and glucose detection. Chemical Communications, 2010, vol. 46, no. 42, pp. 8017-8019.

[18] SUN, A. L. Sensitive electrochemical immunoassay with signal enhancement based on nanogold-encapsulated poly(amidoamine) dendrimer-stimulated hydrogen evolution reaction. Analyst, 2015, vol. 140, no. 23, pp. 79487954. 